\title{
Representações de empreendimentos econômicos solidários sobre a Internet
}

\author{
Representations of joint economic \\ ventures on the Internet
}

Reuber da Silva FONSECA'

Lucília Regina de Souza MACHADO²

\section{Resumo}

A temática deste artigo se insere entre as novas questões geradas pela virtualidade, sobretudo pela crescente migração dos processos comunicacionais e educacionais para a Internet e seu poder de formação de novos espaços institucionais e de novas subjetividades sociais. Seu objetivo central consistiu em conhecer e analisar representações de empreendimentos econômicos solidários de Belo Horizonte (MG) sobre a Internet. Dada a natureza do objeto, foi necessário se beneficiar das abordagens metodológicas quantitativa e qualitativa. O instrumento de coleta de dados utilizado nesse estudo foi o questionário. Concluiu-se, a partir da amostra estudada, que foi intencional e cobriu doze empreendimentos econômicos solidários, que estes demonstram ter representações positivas à inclusão digital, mas não isentas de preocupações e dúvidas sobre o poder e a penetrabilidade dessa tecnologia na sociedade.

Palavras-chave: Autogestão. Cooperativismo. Cultura digital. Economia. Internet.

\begin{abstract}
The theme of this article is positioned between the new questions being posed by the virtual universe, particularly on account of the growing migration of communication and educational processes to the Internet and its power to form new institutional spaces and new social subjectivities. Its core objective was to understand and analyze representations of joint economic ventures, based in Belo Horizonte (Minas Gerais), on the Internet. Given the nature of the subject, it was necessary to benefit from quantitative and qualitative methodological approaches. The data collection instrument used for this study was a questionnaire. It was concluded from the study sample, which was purpose-specific and covered twelve ventures, that they seem to have positive judgments concerning digital inclusion, but are not totally without concern and doubts about the power and pervasiveness of this technology to society.
\end{abstract}

Keywords: Self-management. Cooperatives. Digital culture. Economy. Internet.

\section{Introdução}

Nesta pesquisa buscou-se conhecer e analisar as representações sobre a Internet de empreendimentos econômicos solidários de Belo Horizonte (MG) e apontar benefícios e limites do uso da Internet nos processos de interlocução destes empreendimentos com o mercado e a sociedade.

O advento da sociedade informacional, estruturada sob a metáfora das redes, trouxe a possibilidade de expressão e sociabilização mediada por Tecnologias de

1 Professor, Centro Universitário UNA, MBA em Gestão. R. Guajajaras, 175, 50 andar, Centro, 30180-100, Belo Horizonte, MG, Brasil. Correspondência para/Correspondence to: R.S. FONSECA. E-mail: <reuber@ig.com.br>.

2 Professora Doutora, Centro Universitário UNA, Mestrado em Gestão Social e Desenvolvimento Local. Belo Horizonte, MG, Brasil. Recebido em 17/4/2011 e aceito para publicação em 4/8/2011. 
Informação e Comunicação (TIC). Essa mudança vem estimulando estudos sobre a virtualidade, seus elementos e processos dinâmicos.

Cresce o interesse por verificar se a nova realidade da circulação de informações está contribuindo e de que forma para o surgimento de novos sujeitos sociais e também para construção de novos espaços institucionais de produção e consumo de informações, conhecimentos e saberes, tais como os relativos a Organizações Não-Governamentais (ONG), empreendimentos autogestionários, sindicatos, associações, movimentos sociais e políticos, dentre outros. Especula-se, ainda, se setores que estiveram até então à margem do circuito da informação, como o dos empreendimentos da economia solidária, poderiam, agora, contar com o apoio da Internet como um novo aliado às suas causas e interesses.

Esta investigação se orienta por uma proposição básica, que considera que a representação social da Internet pelos Empreendimentos Econômicos Solidários (EES) influencia o seu uso e os processos de sua apropriação pelos mesmos. Logo, a pergunta que motivou a investigação realizada foi a seguinte: que imagens (concepções e símbolos) EES possuem sobre a Internet, com relação ao significado desta rede para esta modalidade de economia?

Essa pesquisa demandou a participação reflexiva e crítica dos associados/cooperados dos empreendimentos solidários selecionados para este estudo. Daí a importância das duas abordagens metodológicas utilizadas, a qualitativa e a quantitativa, para a obtenção de um entendimento mais amplo e acurado do objeto estudado.

Este plano buscou ir ao encontro da tendência, que se observa no mundo acadêmico, de surgimento de um novo paradigma metodológico, que visa romper com a dicotomia estabelecida entre a concepção positivista, temerosa das contaminações das análises dos fatos sociais por valores subjetivos, e o viés interpretativo, que valoriza o resgate da relação sujeito e objeto nas pesquisas.

A população referenciada compreendeu todos os EES de Belo Horizonte (BH) cadastrados na plataforma Cirandas.net. Outro banco de dados consultado foi o do Centro Público de Economia Solidária (BH).

Como este estudo não pretendeu avançar em aprofundamento e abrangência, mas ter caráter explora- tório, foi definida uma amostra intencional, que atendesse aos propósitos de examinar o problema no seguinte contexto: EES sediados em Belo Horizonte, do setor de produção têxtil e confecção, cadastrados no Atlas da Economia Solidária. Como conceito operacional de EES, utilizou-se o da Secretaria Nacional de Economia Solidária (SENAES), definido em função do cumprimento das seguintes características: a) organizações coletivas e suprafamiliares; b) autogestionárias; c) permanentes (não são práticas eventuais); d) que podem dispor ou não de registro legal, prevalecendo a existência real ou a vida regular da organização; e e) que realizam atividades econômicas principais de produção de bens, de prestação de serviços, de fundos de crédito, de comercialização e de consumo solidário.

O instrumento de coleta de dados utilizado nesse estudo foi o questionário, confeccionado pelos pesquisadores e preenchido pelos informantes, dando início à coleta de dados junto aos 12 EES do ramo de vestuários e acessórios do setor de produção têxtil e confecção de Belo Horizonte (MG), constituindo essa a amostra intencional. A construção do instrumento considerou o trabaIho de Abrantes (2002), adaptado para o objeto de estudo e público-alvo desta pesquisa. O questionário conteve questões em sua grande maioria fechadas, adotando-se o formato da escala Likert de 1-5 em várias delas.

Após o recolhimento, tabulação e tratamento dos dados, passou-se à etapa da análise e interpretação dos elementos considerados relevantes para responder as questões desta investigação. Para a análise dos dados dos questionários utilizaram-se procedimentos estatísticos descritivos e a apresentação por meio de gráfico. Como suporte técnico utilizou-se, basicamente, o software Excelfor Windows.

\section{O contexto de mutabilidade presente na sociedade da informação}

Todos os níveis da vida social, cultural e econômica, em alguma medida, estão sendo afetados pela disseminação das TIC. Elas têm um papel significativo nas possibilidades de acesso, de controle e de armazenamento de informações; são formas de socialização de informação e conhecimento. 
No entanto, assumem também formas de sociabilidade na intermediação das relações interpessoais. As experiências virtuais emergentes afetam as concepções de espaço e tempo, e provocam um redimensionamento das relações interpessoais. Essas, hoje, pautadas pela conexão ou falta de conexão dos indivíduos às redes.

As redes traduzem a lógica de estruturação da sociedade informacional e vêm assumindo um papel estratégico nas relações sociais e econômicas contemporâneas. É importante notar que elas têm por pressupostos relações de confiança e o aporte que cada um traz para seu interior.

No entanto, as redes não estão imunes de conflitos e disputas por poder. As metodologias e tecnologias de ação em rede não são, a priori, uma solução a favor da democratização e do fortalecimento da economia solidária na sua relação com o mercado. Esse potencial se efetiva conforme o uso que os atores fazem delas e a sociabilidade que constroem em suas relações.

A partir dos anos oitenta, no Brasil, as redes eletrônicas disseminaram-se nos movimentos sociais e entre os participantes de organizações da sociedade civil.

O movimento da economia solidária também tem dado provas de seu envolvimento com a promoção dessas iniciativas, quando se percebe que associações, cooperativas de distribuição e serviços, grupos solidários de produção e trabalho experimentam a Internet como um meio para a prática da chamada Economia Solidária.

A Internet está abrindo o mercado para os produtos da economia solidária, que apostam no seu diferencial socioeconômico. É o caso da loja virtual SocialWeb, que vende produtos de organizações não governamentais, entre elas aquelas que estão de acordo com a economia solidária (Lanzarini, 2003).

Portanto, o campo das formas de expressão e ação coletiva em rede apoiada em TIC mostrou-se pertinente a esta discussão, pois ele traduz uma inteligência coletiva dos grupos que têm acesso à Internet e efetivam o potencial deste instrumento no fortalecimento da economia solidária.

As comunidades virtuais, as redes sociais virtuais, os fóruns de discussão, os Weblogs; publicação associada a uma estrutura de pequenos textos com ordem cronológica inversa, com possibilidade de comentários, os wikis; são ferramentas da Internet que permitem a criação colaborativa de conteúdos abertos, o twitter; plataforma que alia o conceito de microblog e redes sociais, são exemplos de ferramentas que servem a expressões e ações coletivas. Estas estão sendo moldadas por meio da sinergia entre as pessoas via rede mundial de computadores, a Internet.

Diante do exposto, surgem questionamentos tais como: o uso de metodologias e tecnologias de expressão e ação coletiva em rede pode fortalecer a economia solidária? A integração dos conhecimentos adquiridos e compartilhados por diversas pessoas, globalmente dispersas, tendentes a desconcentrar os poderes centralizados e hierarquizados e a valorizar a participação de cada indivíduo, proporciona às ações coletivas da Economia Solidária um poder de se multiplicar, com sucesso, pela Internet?

\section{Métodos}

Para a realização desse estudo foi definida uma amostra intencional de 12 empreendimentos do segmento da produção têxtil e confecção, sediados em Belo Horizonte e cadastrados no Atlas da Economia Solidária.

A tabulação dos dados dos questionários revelou que as mulheres são maioria absoluta nos EES deste setor. A pesquisa revelou, ainda, que o número de associados ou cooperados varia entre quatro e, aproximadamente, cinquenta trabalhadores.

Um fato importante a ser considerado é que em conversas informais alguns associados revelaram que os companheiros, filhos e filhas os ajudam, ainda que ocasionalmente, em tarefas tais como: transporte de pessoal, logística de mercadorias e pesquisa na Internet. Mesmo assim, esses "trabalhadores ocasionais" não foram adicionados aos números expostos acima.

A feira parece ser o principal canal de distribuição dos produtos, tendo sido citada por todos os EES consultados. Além da feira, a venda por meio de lojas próprias e a atuação em clubes de compra e troca apareceram na amostragem, ainda que em reduzido número.

Embora a intenção da pesquisa fosse de se ater ao setor de produção têxtil e confecção, os dados mostraram que é alta a diversidade que compõe o mix de produtos dos EES pesquisados. Dentre os principais constam: brinquedos pedagógicos, bolsas, toalhas de mesa, aventais, 
carteiras, garrafas de água, sacolas ecológicas, banners, saias, pintura em tecido, tapetes, barbantes, sapatos, porta-bijuterias, almofadas, 'bate mão', pano de prato, portapães, etc.

Segundo a Associação Brasileira da Indústria Têxtil e de Confecção (2005), o setor têxtil e de confecção nacional compreende mais de trinta mil empresas e gera 1,65 milhões de empregos em toda a sua extensa cadeia produtiva.

A extensão territorial, a variedade cultural, o uso de tecnologias socialmente difundidas e a inexistência de predeterminação da escala de produção permitem que cada região brasileira atue de modo diferenciado, inovando nos meios de produção e no tratamento dos tecidos.

Sejam empresas de micro e pequeno porte, pequenas cooperativas ou grandes corporações, o segmento é de importância estratégica para o desenvolvimento do país. A indústria do vestuário tem como principais características apresentar baixas barreiras de entrada, ser intensiva em mão-de-obra, por sua vez caracterizada pelo predomínio do sexo feminino, "[...] destacando-se também as mulheres como proprietárias, estilistas e gerentes" (Andrade, 2002).

Números apresentados pela Associação Brasileira do Vestuário (Abravest) referentes exclusivamente 3 ao ramo do vestuário, meias e acessórios indicam que o setor oferece 1051772 postos de trabalho e absorve indiretamente um contingente de 4600000 trabalhadores (Associação Brasileira de Vesterinário, 2002).

O uso de tecnologias tradicionalmente difundidas entre o sexo feminino pode explicar a predominância das mulheres no setor de vestuário. Características culturais subjacentes ao desenvolvimento de habilidades, práticas e gostos pela moda podem ser apontadas como fatores desta predominância feminina neste setor.

Apoiando-se em dados da Abravest e do Instituto de Estudos e Marketing Industrial (IEMI), Andrade (2002) revela que as unidades produtivas do ramo de vestuários concentram-se na Região Sudeste e que Minas Gerais detém o terceiro maior número dessas indústrias.

Um estudo sobre o mercado de vestuário no Brasil promovido pelo IEMI, em 2008, revela alguns dados desse ramo contemplando o perfil de suprimento; os canais de distribuição; o perfil da demanda e o poder de compra (Tabela 1).

A roupa e os acessórios, produtos da indústria do vestuário, se caracterizam pela sazonalidade das tendências de modelos, fato típico do campo da moda, determinado por fatores diversos de ordem temporal, cultural, geográfica e mercadológica. Segundo Andrade,

Tabela 1. O Mercado de vestuário no Brasil.

\begin{tabular}{ll}
\hline Perfil de suprimento & Perfil da demanda \\
\hline $1 \%$ vai para a exportação & $70 \%$ é consumido pelas classes B e C (63\% da população) \\
$99 \%$ para o consumo interno & $18 \%$ é consumido pela classe A (5\% da população) \\
Vendas no Varejo alcançaram US\$ 43 bilhões (em 2007) & $61 \%$ do consumo ocorre nas 150 maiores cidades do país \\
105 mil pontos de venda especializados (75\% dos volumes) & Em 12 anos, 30 milhões de consumidores a mais no mercado. \\
8 mil organizados em redes (são 740 redes especializadas) & Resultado: mais consumidores, com maior poder de compra \\
Redes especializadas (1) respondem por 37\% dos volumes & Em 12 anos, a renda per capita aumentou 15\% (em termos reais) \\
As 5 maiores respondem por 11\% do valor total comercializado & \\
Importados alcançaram, em 2007, 3,5\% do volume consumido & \\
\hline Perfil de compra & Canais de distribuição \\
\hline O consumo de vestuário é maior na classe B (39\%), seguido da classe & Grandes lojas varejistas especializadas são o principal canal de \\
C (31\%) & $\begin{array}{l}\text { venda/distribuição } \\
\text { A classe A apresenta a 3a maior fatia }\end{array}$ \\
\hline
\end{tabular}

Fonte: Instituto de Estudos e Marketing Industrial (2008).

3 Não incluídos os demais elos da cadeia têxtil: algodão, fiação, tecelagem e linha lar - cama/mesa/banho. 
"A dualidade da roupa, enquanto bem econômico e simbólico, congrega informações de diversas áreas, como econômica, gerencial, do campo da moda e do contexto sócio-cultural" (Andrade, 2002, p.40).

Essas contingências se fazem presentes desde a concepção da ideia, à produção e distribuição dos produtos para os clientes. Cabe, assim, indagar: que imagens (concepções e símbolos) os EES possuem sobre a Internet com relação ao potencial e significado desta rede para esta modalidade de economia?

\section{Representações de empreendimentos econômicos solidários sobre a Internet}

Por representação entendeu-se, nesse estudo, os recursos de linguagem que os entrevistados dos empreendimentos econômicos solidários selecionaram para descrever ou evocar suas percepções e imagens sobre a Internet. Ou seja, as concepções e símbolos que os entrevistados atribuíram à Internet de modo a sinalizar o significado que esta rede tem para eles.

Para a análise quanti-qualitativa dos dados obtidos, efetuou-se a distribuição de suas frequências utilizando-se o Ranking Médio (RM). A equação abaixo traduz o cálculo da média, tomando-se as frequências como peso para os valores das medidas ponderadas na base da categoria de opinião:

Ranking Médio (RM) = $\Sigma$ (frequência da categoria de opinião) x (escala atribuída)

Total de opiniões

Realizou-se a verificação da concordância ou discordância dos respondentes com relação às questões postas à avaliação por meio do cálculo do RM da pontuação atribuída às respostas. Os valores menores que zero, encontrados por meio desse cálculo, serviram para sinalizar avaliações discordantes e, maiores, as concordantes, considerando-se a escala utilizada de cinco pontos. O valor zero correspondeu à alternativa "sem opinião" ou "recusaram-se a opinar".

A escala atribuída às afirmações ficou assim definida:-2: Discordo totalmente;-1: Discordo parcialmente; 0 : Não concordo, nem discordo; 1: Concordo parcialmente; 2: Concordo totalmente. Foram submetidas à avaliação 24 afirmações, sendo que oito delas foram afirmações no sentido negativo. Na tabulação destes dados, então, a escala atribuída foi invertida e ficou assim estabelecida: 2 : Discordo totalmente; 1: Discordo parcialmente; 0: Não concordo, nem discordo; -1: Concordo parcialmente; -2: Concordo totalmente.

Buscou-se analisar as assertivas em conjunto, por critério de proximidade simbólica das questões.

A Figura 1ilustra os resultados gerais dos 24 aspectos submetidos à apreciação dos EES. As afirmações negativas sobre a Internet estão contempladas nas barras horizontais superiores e as positivas nas barras horizontais inferiores. Em ambos os casos, foi observada a ordem ascendente de incidência dos números construídos pelo Ranking Médio (RM). Pode-se observar que nenhum dos aspectos atingiu 100,0\% de concordância (RM $=+2$ ) ou de discordância $(R M=-2)$, sendo relativamente pequena a situação na faixa negativa ( $0>$ RM $>-2$ ). Percebe-se que $87,50 \%$ dos aspectos analisados se encontram na faixa positiva $(0<\mathrm{RM}<+2)$, indicando uma imagem positiva da Internet pelos EES pesquisados. A leitura permite afirmar que a Internet é reconhecidamente vista como uma revolução pelos respondentes. Essa assertiva ocupou o primeiro lugar no Ranking Médio $(\mathrm{RM}=+1,75)$ aproximando-se da plena concordância $(\mathrm{RM}=+2)$.

Os respondentes se manifestaram favoráveis à ideia de que a Internet é revolucionária. De fato, por ela, qualquer pessoa pode acessá-la e publicar informações. Como princípio, o direito de acesso livre deveria ser garantido a todos, inclusive aos que não possuem recursos financeiros e materiais.

Por outro lado, sabe-se que é preciso tomar muito cuidado, justamente pelo mesmo motivo: informações distorcidas ou falsas podem ser publicadas por pessoas com interesses duvidosos. Considerar a Internet como mídia totalmente revolucionária no sentido de fomento da democracia também exige cautela, porque tentativas de controlá-la não são poucas, apesar de não reconhecerse ainda uma única experiência positiva neste sentido.

Quando perguntados se a Internet é uma perda de tempo, os EES se posicionaram contrários a esta ideia $(\mathrm{RM}=+1,42)$. Ainda que 58,0\% tenham discordado parcialmente, demonstrando, portanto, a existência de algum nível de desconfiança para com a Internet, a assertiva não recebeu um único voto concordante, nem neutro. 


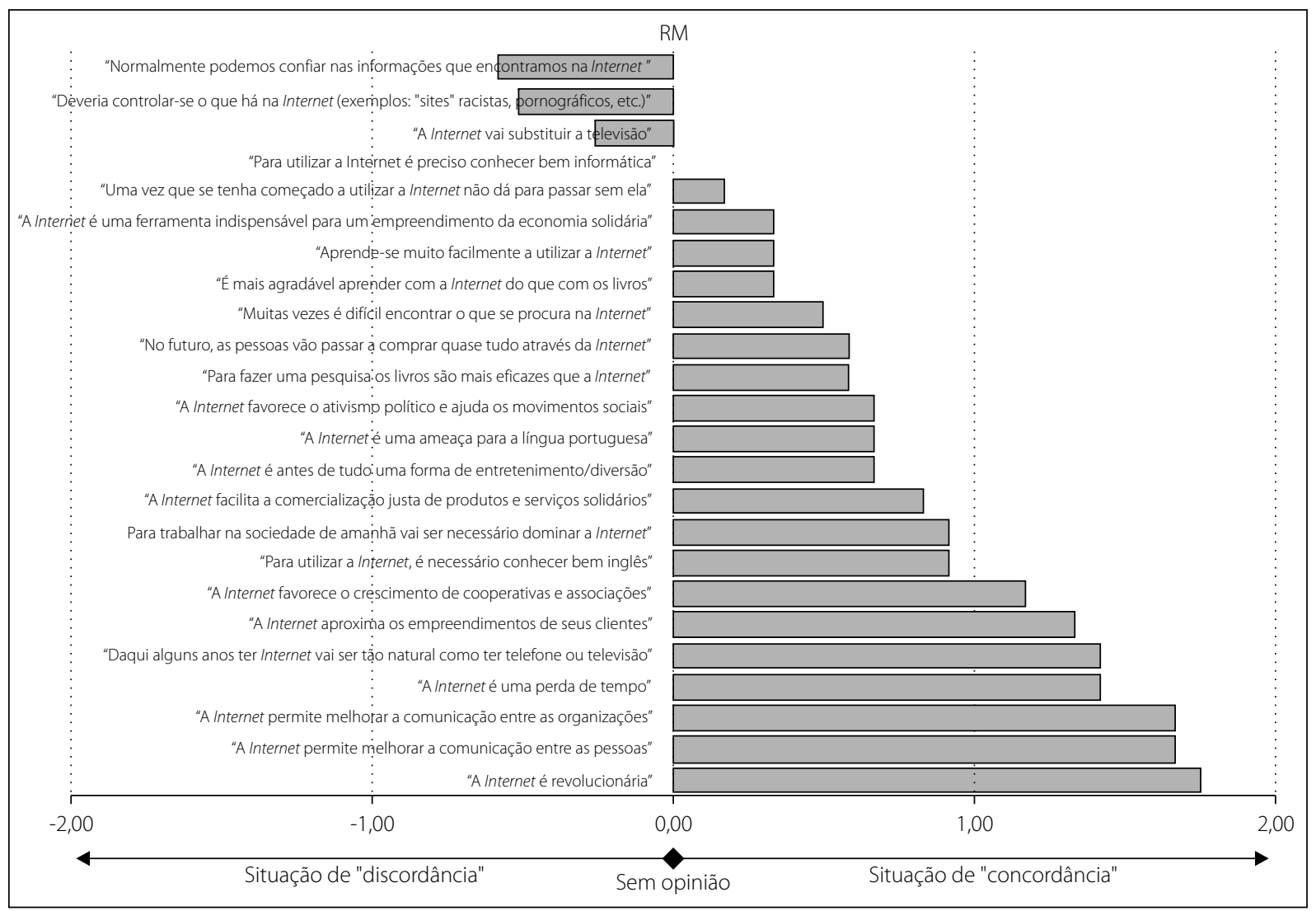

Figura 1. Diagrama de Pareto das representações sobre a Internet, construído pelo Ranking Médio.

Nota: A figura ilustra os resultados gerais dos 24 aspectos submetidos à apreciação dos EES. As afirmações negativas sobre a Internet estão contempladas nas barras horizontais superiores e as positivas nas barras inferiores. Em ambos os casos, foi observada a ordem ascendente de incidência dos números construídos pelo Ranking Médio.

Os mesmos percentuais $(58,0 \%)$ de EES discordaram quando perguntados se a Interneté antes de tudo entretenimento e diversão. Isso implica dizer que os EES do setor de confecções de Belo Horizonte conferem à Internet uma importância maior, e que essa ultrapassa a noção de espaço de entretenimento e lazer, ainda que também possa ser representada assim. Isso ficará mais evidente nas análises que se seguem.

Complementarmente à análise desenvolvida acima, a visão dos EES é de que a Internet é eficiente na melhoria da comunicação tanto pessoal quanto organizacional, seu poder revolucionário nesse sentido parece ser muito visível para eles. Os empreendimentos solidários pesquisados concordaram com as assertivas ( $R M=1,67)$, ainda que 33,0\% deles concordem parcialmente com a assertiva no que se refere às pessoas.
Mudanças operadas na comunicação interpessoal e organizacional, acarretadas pela Internet, são pontos visíveis e amplamente debatidos, pois a produção de conteúdo online se tornou bastante acessível, sendo possível veicular todo tipo de mídia (texto, foto, som, vídeo, multimídias etc.), além de permitir a construção dos conteúdos em vários "estilos" (jornalístico, documentário, musical etc.).

De fato, a facilidade de exposição de ideias em diversos estilos proporciona uma variedade enorme de opções de conteúdos por meio da Internet, em contraste com os tradicionais veículos de mídia (televisão, jornal, rádio etc.), presos nos espectros eletromagnéticos de transmissão ou no suporte midiático que requerem para veicular sua produção.

Um estudo recente realizado pela PostRank, uma empresa que monitora acontecimentos e que coleta 
informações correlacionadas com o conteúdo online na Web, mostra como as pessoas estão se comunicando e o que vem mudando na comunicação social. A adesão à comunicação tempo real cresce anualmente 30\%. Em 2008, o estudo registrou 342 milhões de pessoas se comunicando por meio de mídias ou ferramentas sociais. No ano de 2009, esse número pulou para 588 milhões de internautas que compartilham informações ou debatem em rede. Mais do que nunca pessoas estão compartilhando, re-tweeting e inserindo links em conteúdos. A profundidade desse envolvimento e a frequência das comunicações ficam evidentes quando se analisam os contundentes números das principais mídias sociais: por minuto são enviados seis mil tweets, duzentos comentários são publicados no Wordpresse 150 bookmark são fixados no Delicious (How..., 2010).

O uso da comunicação tem se mostrado, assim, imprescindível às organizações nas suas diversas dimensões: interna, institucional, de captação de recursos, de prestação de contas, de promoção, entre outras. Em todas elas, os processos comunicacionais das organizações precisam dar ênfase ao aspecto relacional.

A Comunicação Mediada por Computador (CMC) possibilita a troca de informações, em tempo real, entre pessoas de diferentes localidades geográficas, possibilitando a criação da rede. A comunicação neste ambiente pode dar-se de "um-para-um", "um-para-muitos" ou até mesmo "muitos-para-muitos" e é aí que se encontra o grande diferencial da Internet em relação aos outros meios de comunicação: a capacidade de interatividade e a construção de relações.

Contudo, estariam os empreendimentos solidários pesquisados conscientes dessas possibilidades? Estariam eles engajados nessa cultura digital, compartilhando saberes, colaborando coletivamente e comunicando sua ética solidária ao mercado e à sociedade?

Quando questionados sobre a eficácia dos livros, frente à Internet, na recuperação de dados, como se requer em pesquisas, os EES se dividiram, havendo certo equilíbrio entre os que discordam (58,3\%) e os que concordam $(41,7 \%)$. O Ranking médio dessa assertiva foi de apenas $+0,58$.

A curiosidade deste resultado está relacionada à consagrada agilidade que a Internet possui na recuperação de dados, principalmente, quando do surgimento e aprimoramento dos mecanismos de busca, solução essa de grande uso e valor aos que navegam e pesquisam na Web a partir de palavras-chave.

A Internet facilita o trabalho de pesquisa porque a informação vem em tempo real, de fontes globalmente localizadas. O internauta tem acesso a livros eletrônicos, materiais didáticos, apostilas, apresentações, vídeos etc., na comodidade do lar, do escritório, ou em qualquer outro lugar coberto por conexão a rede sem fio.

De fato, o acesso à produção científica também é um marco qualitativo da rede, acumulando experiências de divulgação e construção colaborativa de material didático de livre acesso. Neste sentido, o Instituto Brasileiro de Informação em Ciência e Tecnologia (IBICT) lançou o projeto do Portal de Livros Didáticos Eletrônicos, em fase de implementação pelo Ministério da Ciência e Tecnologia (MCT). O Livro Didático Público, desenvolvido pelo Projeto Folhas da Secretaria da Educação do Estado do Paraná e a Wikilivros também são experiências que buscam oferecer material didático de livre acesso (Mochiute, 2009).

No sentido do ditado que diz que "uma imagem vale mais que mil palavras", o Google lançou recentemente mais um aplicativo relacionado à busca de informações na Internet, só que usando imagens. Ele se chama Google Goggles e permite ao usuário de celulares e de outros dispositivos móveis que rodam o sistema operacional Android 1.6 ou superior, apenas "apontar" o celular e fotografar ao invés de digitar seus critérios de pesquisa (palavras-chave). A busca visual é uma tecnologia ainda incipiente, mas já permite a pesquisa de marcos históricos e turísticos, capas de livros, obras de arte, etc. Assim, para esse tipo de pesquisa, não importam a língua e a ortografia local.

Ao se confrontarem com a assertiva: "É mais agradável aprender com a Internet do que com os livros", mais uma vez os dados obtidos revelam certo equilíbrio entre os respondentes. Concordaram com a afirmação 50\% deles; o restante se dividiu em discordantes (33,3\%) e não souberam opinar (17,3\%).

Certamente, a Internet ajuda na democratização do aprendizado. Desde seu início, experiências que visavam testar seu potencial como ambiente de aprendizagem vem sendo construídas com relativo sucesso. Os Ambientes Virtuais de Aprendizagem (AVA) permitem que o aluno seja ativo no processo de aprendizagem e tenha o controle de seus estudos. Os aprendizes participam das 
aulas por meio de chats, de portfólios, de vídeo-aula, de fóruns de discussão e os utilizam com outros alunos para esclarecer dúvidas, que são mediadas por tutores, monitores ou professores. Por meio destas ferramentas, os próprios alunos podem responder às dúvidas dos colegas, contribuindo coletivamente para a produção e uso do conhecimento.

Assim sendo, a Internet é uma ferramenta poderosa para o aprendizado, mas requer leitura, pesquisa, contextualização, comparações, como em qualquer outro ambiente de aprendizado - o que pode significar barreiras ao seu acesso.

Em um espaço tão promissor para a educação formal (assim como para a experimentação de novas relações com o saber e o aprender), a Internet é, frequentemente, acusada por alguns linguistas, educadores e pensadores de toda a ordem de ser um território com pouca preocupação com os aspectos formais da língua.

É visível em comunicação por meio de aplicativos ou sistemas de Mensagem Instantânea (IM), tais como o MSN, ICQ, e o Yahoo Messenger, o uso de abreviações; forma de grafia que tenta imitar a linguagem infantil; emoticons; e outros símbolos utilizados para agilizar a escrita e a comunicação.

No entanto, ao contrário do que muitos pensam, algumas formas de escrever podem ser ainda mais trabalhosas do que a escrita normal, como o recurso comum de alternar letras maiúsculas com minúsculas.

Por ser um assunto polêmico, foi introduzida na pesquisa de que trata este artigo uma questão que buscou saber se os respondentes viam na Internet uma ameaça à língua portuguesa. O resultado indica que 75,0\% dos EES discordam desta possibilidade. Este resultado talvez tenha a ver com o fato de poucos relatarem utilizar os IM e chats, onde os desvios de linguagem estão mais presentes.

Apesar de indicarem que a Internet é revolucionária, que melhora a comunicação e que facilita o aprendizado por meio dela, os respondentes mostraram-se divididos (50,0\% concordam e outros 50,0\% discordam) sobre a assertiva que buscou saber se é muito fácil aprender a utilizar a Internet. Com RM=+0,33 essa assertiva se aproximou da opção neutra ( $R M=0)$ e poderia representar o motivo pelo qual 58,3\% do EES pesquisados não utilizarem a Internet no seu esforço de produção, comercialização e distribuição da produção.

Pelos dados obtidos na pesquisa realizada não se pode concluir que essa dificuldade de aprendizagem tem a ver com a existência de vernáculos em língua estrangeira na Internet, flagrantemente em inglês. Afinal 67,0\% dos EES discordaram da afirmativa que para utilizar a Internet é importante conhecer bem esse idioma. Por outro lado, 42,0\% dos respondentes associaram a necessidade de conhecer bem a informática à barreira ao uso da Internet. Essa assertiva apresentou RM=0, posicionando-se em quarto lugar no ranking, próximo das assertivas que foram avaliadas como negativas na Internet.

Entre as assertivas submetidas à avaliação pelos EES, duas se destacaram na revelação de imagens negativas da Internet. Quando os EES se depararam com as afirmações do tipo: deveria controlar-se o que há na Internet [...] e não se pode confiar nas informações que encontramos na Internet, foram obtidas respostas bem conservadoras, no sentido da necessidade de controle da rede e denunciando a falta de credibilidade nas informações veiculadas. Uma crítica mais consistente destas questões é apresentada à frente.

Por hora, apresenta-se uma análise das assertivas relacionadas com a dificuldade de se achar o que se procura na Internet e se a Internet se torna indispensável no dia-a-dia dos usuários.

Os pesquisados posicionaram-se contrários à assertiva: "Muitas vezes é difícil encontrar o que se procura na Internet". No Ranking Médio essa afirmação recebeu a pontuação $+0,50$, indicando que as respostas a esta questão não foram hegemônicas. Verificou-se que 33,3\% dos EES não souberam ou quiseram opinar sobre a questão e que $25,0 \%$ opinaram a favor da assertiva, indicando uma dificuldade de se achar o que se procura.

Esse resultado indica que apesar dos vários aplicativos e sistemas de busca alojados na Internet, principalmente na Web, os resultados das pesquisas nestes sistemas podem não refletir o que se deseja saber, em termos de precisão, confiabilidade, formato da informação, etc.

O resultado para a assertiva:"Uma vez que se tenha começado a utilizar a Internet não dá para passar sem ela" apresentou-se muito próximo ao ponto médio, com $\mathrm{RM}=+0,17$. Isso indica que a Internet para os EES pesquisados não é percebida como elemento intrínseco e imprescindível às atividades do seu dia-a-dia. 
Esse resultado será retomado quando da análise da assertiva que busca compreender se a Internet é uma ferramenta indispensável para um empreendimento da economia solidária.

Quando questionados se a Internet substituirá a televisão, os pesquisados revelaram discordar da assertiva ( $R M=-0,25)$, ostentando que a Internet ou não concorre com a televisão ou que ainda concorrente, a televisão permanecerá como veículo de mídia.

Contudo, apesar de contrários à ideia de substituição da televisão e pouco favoráveis à Internet constituir-se elemento indispensável às suas atividades, os EES posicionaram-se fortemente a favor da afirmação de que daqui a alguns anos ter Internet vai ser tão natural como ter telefone ou televisão $(\mathrm{RM}=+1,42)$.

Quando se observa como esses dois últimos elementos estão, intrinsecamente, ligados à cultura brasileira, não seria de se estranhar que a presença da Internet, tornando-se tão natural, não iria incorporar-se, da mesma maneira, no dia-a-dia das atividades dos EES? Estariam, então, esses assumindo uma postura de negação do valor da Internet no seu dia-a-dia, como artifício de defesa frente às mudanças que a incorporação deste elemento causaria em seus processos, no relacionamento com o mercado, nos saberes arraigados etc.? Ou seriam os EES possuidores de uma visão que não compreende as potencialidades da Internet, já tão disseminadas na literatura científica e incorporadas pelo senso comum? Ou ainda, mesmo compreendendo-as se recusam a dialogar com a cultura digital por meio da Internet?

Reforçando o valor do questionamento acima, os pesquisados concordaram com a assertiva que relaciona o comportamento de compra no futuro e o poder da Internet de oferecer o que se deseja ou necessita. Frente a essa ideia, os EES concordaram que as pessoas vão passar a comprar quase tudo por meio da Internet ( $\mathrm{RM}=+0,58)$.

Isso implica dizer que eles acreditam que a Internet participará ativamente de um dos atos mais corriqueiros do dia-a-dia, o da compra. Como poderiam então acreditar, tão acanhadamente, que não dá para viver sem ela?

As assertivas agrupadas na figura acima revelam, entre outras coisas, que o fato dos respondentes acreditarem na necessidade de dominar a Internet para trabalhar na sociedade de amanhã $(\mathrm{RM}=+0,92)$; que a Internet aproxima os empreendimentos de seus clientes $(\mathrm{RM}=+1,33)$; que favorece o crescimento de cooperativas e associações ( $R M=+1,17)$; e que facilita a comercialização justa de produtos e serviços solidários ( $R M=+0,82)$, eles não apresentam firmes convicções sobre a indispensabilidade da Internet para a economia solidária $(\mathrm{RM}=+0,33)$.

Esses dados revelam que há uma desconfiança para com a Internet, ainda que não possa ser possível estabelecer relações de causalidade.

Que conclusão chegar ao se deparar com uma imagem, a princípio, contraditória, representada, por um lado, pelo reconhecimento da Internet como revolucionária, que aproxima os empreendimentos de seus clientes, que favorece o cooperativismo e associativismo e a comercialização justa de produtos e serviços solidários; e por outro lado, pela desconfiança de que esse mesmo instrumento não se tornou indispensável para esses empreendimentos econômicos solidários, posto que, essa forma de organização econômica está fundamentada no trabalho associado ou cooperado e na produção e comercialização justa de produtos e serviços?

Quando apresentados à assertiva da Internet favorecer o ativismo político e ajudar os movimentos sociais, percebe-se uma concordância dos entrevistados $(\mathrm{RM}=+0,67)$. Contudo, é significativo o número de EES que não quiseram ou não souberam opinar a este respeito (33,3\%).

Dentre os aspectos analisados como negativos sobre a Internet, destaca-se a desconfiança nas informações encontradas neste ambiente ( $R M=-0,58)$. As oportunidades plurais de acesso, produção e disseminação de conteúdos, muitas vezes expressos por opinião própria em blogs, fóruns e outros espaços de discussão, transformariam a Internet num domínio da livre comunicação, extinguindo algumas barreiras sociais e fronteiras geográficas. O que se segue à grande quantidade de informação que circula hoje na grande rede é o imperativo de que cada um saiba selecionar as melhores e mais confiáveis fontes de informação, ainda que os passos para o desenvolvimento dessa habilidade não estejam muito claros.

Outro aspecto negativo para os pesquisados é aquele relacionado à necessidade de controle do conteúdo da Internet ( $\mathrm{RM}=-0,50)$, uma vez que, como domínio 
de livre comunicação, a Internet estaria a serviço da inexperiência, improbidade ou malícia de pessoas ou grupos que se utilizam da rede para a expressão de ideias e práticas discriminatórias, atos ilícitos e, ainda, pensamentos não hegemônicos.

Todavia, a defesa do controle destes conteúdos impõe várias questões, entre elas: 1) Sabendo que a Internet não se restringe a uma nação - nem a uma união dessas e nem pode ser concebida como propriedade intelectual de alguém, quem (ou o que) deveria controlar o seu conteúdo? 2) Quais categorias seriam utilizadas para discernir entre o legítimo exercício da liberdade de expressão de ideias não hegemônicas e as práticas que geram prejuízo à propriedade ou imagem de alguém? 3) No meio de tanta diversidade de ofertas informativas não seria mais democrático e efetivo demarcar, claramente, a presença na Internet do pensamento divergente da pessoa/grupo prejudicado, em vez de limitar a condenar a má comunicação social ou tentar controlar o acesso a conteúdos e/ou o direito a produzi-los?

Estar conectado é se dispor a relacionar-se consigo mesmo e com os outros numa complexa teia de dúvidas, hesitações e problemáticas. Nesse sentido, o conflito é inevitável e revela-se na informação que se lê e igualmente na que se produz.

Na análise do terceiro aspecto representado como negativo percebe-se que há um desacordo com a afirmação que tenta admitir a obsolescência da televisão frente à inovação da Internet. Os EES responderam não acreditar que a Internet possa substituir a televisão (RM =-0,25). Infere-se que a Internet e seus serviços contemporâneos, para os pesquisados, não se confundem com a televisão e podem conviver harmonicamente. Por outro lado não se pode negar o movimento de convergência para a Internet de conteúdos e programações de outras mídias, inclusive a televisão. A TV pelo streaming ${ }^{4}$ por meio da Internet é uma opção tecnológica crescente ejá deixou de ser um passatempo para geeks ${ }^{5}$ e aficionados por novas tecnologias. Permite-se escolher entre milhares de canais, em tempo real, e decidir quais programas utilizar para visualizar as TVs em streaming. No entanto, a qualidade da transmissão depende da velocidade e da qualidade da conexão à Internet.

Os efeitos deste movimento já são estudados ${ }^{6} \mathrm{e}$ podem estar por trás da diminuição, apurada nos últimos anos, da audiência das grandes redes de televisão. As novelas criaram hábitos nos telespectadores e o veículo sempre esteve presente nas grandes questões de interesse político-social, inclusive interferindo nos acontecimentos, como na campanha para o impeachment do então presidente Fernando Collor.

\section{Conclusão}

Verifica-se, a partir da amostra estudada, que empreendimentos da economia solidária do setor de vestuário de Belo Horizonte apresentam representações positivas à inclusão digital, representada pelo uso da Internet, mas que tal posicionamento não é isento de preocupações e dúvidas sobre o poder e a disseminação dessa tecnologia na sociedade.

Os empreendimentos pesquisados acessam a Internet, mas mantém estilos de gestão tradicionalmente usuais, embora as teorias afirmem que a emergência das TIC inaugura uma nova cultura (a cultura digital).

Logo, percebe-se que entre os dados encontrados e as expectativas teóricas há defasagens, desencontros e contradições. A pesquisa realizada, de natureza exploratória, pretendeu sondar questões que ainda precisam ser mais pesquisadas e estudadas. Neste sentido, propõe-se que investigações posteriores considerem sete hipóteses:

\section{1) Relação custo $x$ benefício}

A organização autogestionária pressupõe um equilíbrio das forças de trabalho entre aqueles que parti-

4 Uma forma de distribuir informação multimídia numa rede de computadores através de pacotes.

5 Usuário avançado de tecnologias de informação e comunicação, especialmente da Internet. Culturalmente adaptado a virtualidade e ao digital.

- A pesquisa O Futuro da Mídia, realizada em outubro de 2008, pela Deloitte e pelo Harrison Group, empresa independente dos EUA, concluiu que enquanto a televisão continua na preferência de entretenimento de mais de 66\% dos pesquisados nos EUA, Inglaterra, Alemanha e Japão, no Brasil esse índice é de 46\%. A pesquisa confirma mudanças de hábito no país e mostra a força da Web como mídia. A experiência de assistir à TV, enquanto o telespectador faz outras atividades demonstra o grau de dispersividade do telespectador, o que faz da TV um mero coadjuvante como veículo de informação e entretenimento. 
cipam das atividades econômicas. Logo, alguns trabalhadores reagem negativamente à investida da cultura digital, uma vez que isto pressupõe uma mobilização de tempo e trabalho cujo retorno não está muito claro aos participantes desta modalidade de economia.

\section{2) Conflitos na concepção de trabalho: o trabalho intangível (intelectual) x tangível (produtivo-ope- racional)}

A inserção na cultura digital introduz novas tarefas, rotinas e processos. Alguns desses intangíveis, de difícil mensuração, como por exemplo, a função da pesquisa. Isso poderia ser alvo de críticas por aqueles que comungam de uma cultura tradicional, que contabilizam os ganhos somente na produção tangível, isto é, na quantidade de produtos produzidos. Assim evita-se o uso e a apropriação da Internet porque este grupo pode ser estigmatizado como preguiçoso e acusado de não compartilhar dos esforços coletivos da produção.

\section{3) A instabilidade dos laços econômicos na modali- dade solidária}

A Economia Solidária vista pelo viés da complementação da renda, portanto, como uma atividade periférica, "um bico", implica em vínculos trabalhistas instáveis e uma preferência por capacitações cujos retornos sejam imediatos. Esse cenário favorece um comportamento reativo frente à necessidade de mudança de hábitos e desenvolvimento de novas competências e habilidades que a cultura digital estabelece.

\section{4) Economia Solidária não estimula a competiti- vidade}

O discurso teórico corrente explica o surgimento das TIC e defende a sua apropriação devido à lógica da competitividade. Contudo, a economia solidária pressupõe formas alternativas de organização e se fundamenta na ética da solidariedade. A competitividade cede o lugar à mútua cooperação, à solidariedade, ao amor. Uma economia pautada nesta premissa não carece fazer uso das TIC para aumentar a produtividade, a inovação e a competitividade.

\section{5) A sociabilidade afetuosa das feiras}

Muitas das resistências se depositam na durabilidade da cultura da feira como um patrimônio social. A feira como expressão visível do mercado em rede, das trocas tácitas, do calor humano. A feira como tecnologia de organização de mercados, socialmente difundida na Economia solidária, onde os EES constroem relações de sociabilidade mais afetuosas que aquelas mediadas pelas TIC.

\section{6) A autoimagem e a pró-atividade}

A crença das pessoas em seu potencial para benefício próprio, de terceiros e de tudo ao seu redor representa a pró-atividade. Os trabalhadores da economia solidária apresentam uma autoimagem negativa, uma sensação baixa de autoeficácia. As pessoas que assim se consideram têm maior dificuldade para empreender ações de inserção na cultura digital porque se sentem incapazes de se apropriar da Internet para solucionar seus problemas.

\section{7) Questões de gênero e tecnologia}

A ciência e tecnologia foram, por muito tempo, vistas como atividades masculinas. As relações de gênero, permeadas pelas relações de poder, levaram à definição de profissões que seriam atribuídas às mulheres. O uso de tecnologias socialmente difundidas entre as mulheres, no setor de vestuário, pode explicar a desconfiança dessas no uso detecnologias avançadas na dimensão do trabaIho. Isso porque, por vezes, essas tecnologias replicam as relações de poder e substituem as relações humanizadas que essas dispõem no setor.

A população estudada é rica de conhecimentos (opiniões, valores e atitudes), contudo, estes conhecimentos é que vão se constituir, muitas vezes, em barreiras à adoção de novas tecnologias.

As informações obtidas apontam para a necessidade de novas pesquisas. Esta permitiu constatar que o número de publicações sobre o tema é ainda muito pequeno diante da importância do problema, reforçando a necessidade de novas pesquisas. 


\section{Referências}

ABRANTES, J.C. (Coord). Os jovens e a internet: representação, utilização, apropriação. Coimbra: Faculdade de Letras da Universidade de Coimbra, 2002. Disponível em: <http:// www.bocc.ubi.pt/pag/abrantes-jose-carlos-jovens-Internet. html>. Acesso em: 5 jul. 2009.

ANDRADE, M.E.A. A informação e o campo das micro e pequenas indústrias da moda em Minas Gerais: a entrada no campo da indústria da moda. Perspectivas em Ciência da Informação, v.7, n.1, p.39-48, 2002.

ASSOCIAÇÃO BRASILEIRA DA INDÚSTRIA TÊXTIL E DE CONFECÇÃO. Apresenta dados gerais do setor têxtil. Disponível em: <http://www.cedro.ind.br/br/downloads/investidores/ ABIT2008.pdf>. Acesso em: 22 dez. 2009.
ASSOCIAÇÃO BRASILEIRA DE VESTUÁRIO. Estrutura da cadeia produtiva têxtil. 2002. Disponível em: <http://www.abravest. org.br>. Acesso em: 22 dez. 2009.

HOW social engagement is changing. Ontario: PostRank 2010. Available from: <http://www.postrank.com/blog >. Cited: 6 Apr. 2010.

INSTITUTO DE ESTUDOS E MARKETING INDUSTRIAL. Relatório setorial da indústria têxtil brasileira, v. 8, n. 8, 2008.

LANZARINI, J. Vendas pela internet ajudam a alavancar economia solidária no país. Jornal do Brasil, 31 mar. 2003. Disponível em: <http://www.fbes.org.br/boletins/3.htm>. Acesso em: 20 mar. 2007.

MOCHIUTE, T. Conteúdo didático que aproveita potencial da Internet facilita acesso ao conhecimento. 2009. Disponível em: <http://aprendiz.uol.com.br/content/brogodoloc.mmp>. Acesso em: 25 mar. 2009. 